\title{
A New Design of Compact $4 \times 4$ Butler Matrix for ISM Applications
}

\author{
Mbarek Traii,, ${ }^{1}$ Mourad Nedil, ${ }^{2}$ Ali Gharsallah, ${ }^{1}$ and Tayeb A. Denidni ${ }^{3}$ \\ ${ }^{1}$ Laboratory of Electronic, Faculty of Sciences of Tunis, Tunis El Manar University, 2092 Tunis, Tunisia \\ ${ }^{2}$ Laboratoire de Recherche Télébec en Communications Souterraines LRTCS 450, 3e Avenue, \\ Local 103 Val-d'Or (Québec), Canada J9P 1S2 \\ ${ }^{3}$ INRS-EMT, Université de Québec, Place Bonaventure 800, de la Gauchtière Ouest West, Suite 6900, \\ Montréal, QC, Canada H5A 1 K6
}

Correspondence should be addressed to Mbarek Traii, traii_moncef@yahoo.fr

Received 5 May 2008; Revised 9 September 2008; Accepted 22 December 2008

Recommended by Kenjiro Nishikawa

A novel design of a compact $4 \times 4$ Butler matrix is presented. All the design is based on the use of a Lange coupler with certain geometrical characteristics. This matrix occupies only $20 \%$ of the size of the conventional Butler matrix at the same frequency ( $80 \%$ of compactness). To examine the performance of the proposed matrix, the Lange coupler and the Butler matrix were simulated using Momentum (ADS) and IE3D softwares. Simulation results of magnitude and phase show a good performance. Furthermore, a four-antenna array was also designed at $2.45 \mathrm{GHz}$ and then connected to the matrix to form a beamforming antenna system. As a result, four orthogonal beams at $-45^{\circ},-15^{\circ}, 15^{\circ}$, and $45^{\circ}$ are produced. This matrix is suitable for wireless application at ISM band of $2.45 \mathrm{GHz}$.

Copyright (C) 2008 Mbarek Traii et al. This is an open access article distributed under the Creative Commons Attribution License, which permits unrestricted use, distribution, and reproduction in any medium, provided the original work is properly cited.

\section{Introduction}

Smart antenna systems have been introduced to improve wireless performance and to increase system capacity by spatial filtering, which can separate spectrally and temporally overlapping signals from multiple users. Switched beam systems are referred as antenna-array systems that form multiple-fixed beams with enhanced sensitivity in a specific area. This antenna system detects signal strength, selects one of the several predetermined fixed beams, and switches from one beam to another as the user moves. One of the most widely known of switched beam networks is Butler matrix [1]. It is an $N \times N$ passive feedingnetwork with beam steering capabilities for phased array antennas with $N$ outputs and $N$ inputs. Feeding an $N$-element antenna array using an $N \times N$ Butler matrix, $N$ orthogonal beams can be generated, and each beam has a gain of the whole array.

In most cases, circuits are designed using branch-line directional couplers [2]. However, in single-layer Butler matrix, hybrid coupler takes up over $50 \%$ of the area. It has a dimension of a quarter wavelength square and occupies a significant amount of the board area. For reducing the area, some techniques such as the use of lumped-element [3] have been proposed. However, lumped inductors and capacitors with the required values are not always available and their tolerance is quite larger. Thus, the need for compact circuits with simple structure and low cost is more and more attractive.

The problem of miniaturization was reported in [4], where semilumped branch-line couplers have been proposed. The broadband $3 \mathrm{~dB}$ coupled line directional couplers were used in [5]. In this case, a small size has been achieved but the bandwidth of the Butler matrix is limited by differential phase characteristics. In [6], the authors have proposed a stripline Butler with broadband differential phase matrix. However, the stripline technique presents high manufacturing costs and complexity [7]. The most attractive technique for designing and manufacturing microwave circuits is a microstrip technique since it uses a single laminate layer and allows easy mounting of surface mount devices and components. 
In this contribution, a new design of a compact Butler matrix based on Lange coupler and Lange crossover is proposed and described. This matrix is advantageously used to offer a compact structure with low cost. In addition, the significant size reduction achieved with high performances with low loss compared to the conventional Butler matrix design. To have a prevalidation of the proposed design, the proposed Butler matrix has been simulated with using two softwares Momentum (ADS) and IE3D. Simulation results including return loss and insertion loss are presented and discussed. Furthermore, to examine the performance of the proposed matrix in terms of beamforming, a four-antenna array was connected to this matrix to form a multiple beam antenna system at $2.45 \mathrm{GHz}$. Simulations were carried out on this beamforming system and the obtained results are also presented and discussed.

\section{Butler Matrix Design}

A standard $N \times N$ Butler matrix has $N$ input and $N$ output ports. Matrices with $90^{\circ}$ hybrids are symmetrical networks, whereas those with $180^{\circ}$ hybrids are asymmetrical [8]. For each input port, the network will produce signals with progressive phase shifts at the output ports with equal power. As a result, this matrix produces $N$ orthogonal beams at its outputs.

The Butler matrix system also works in a reverse manner. An incident plane wave from a specific direction produces the appropriate phase difference that will give RF power only at one input port [9]. This can lead to the implementation of various algorithms that derive the direction of arrival of the incident signal. Butler matrices operate like an FFT algorithm. If the linear array of the Butler matrix is on the $z$ axis, the beams produced are directed [10] as follows:

$$
\theta_{p}=\sin ^{-1}\left(\frac{\psi_{p}}{\beta d}\right)
$$

where

$$
\psi_{p}=\frac{2 p-1}{N} \pi
$$

where $p$ is the beam number, $p \in\{0, \ldots, N-1\}$, and $N$ is the maximum number of beams.

Figure 1 shows the proposed $4 \times 4$ Butler matrix that uses microstrip Lange couplers (directional couplers), Lange crossovers, and phase shifters. The key components of the proposed compact Butler matrix are the directional Lange coupler and Lange crossover. Using the EM simulators, the design procedure of the Lange coupler, Lange crossover, and the $4 \times 4$ Butler matrix were carried out. In the following sections, the design and the performance of each component of this matrix are presented and described in more detail.

\subsection{Lange Coupler Design}

The proposed Lange coupler with symmetric structure is composed of several parallel lines with alternate lines tied together as shown in Figure 2. It is necessary to bond directly,

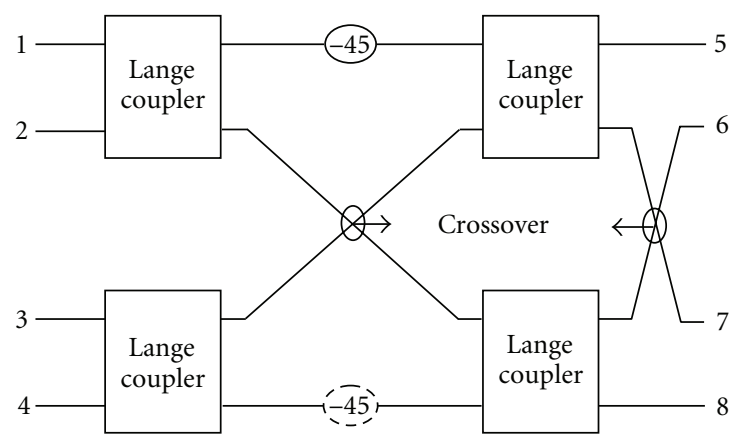

FIGURE 1: Schematic diagram of the proposed $4 \times 4$ Butler matrix.

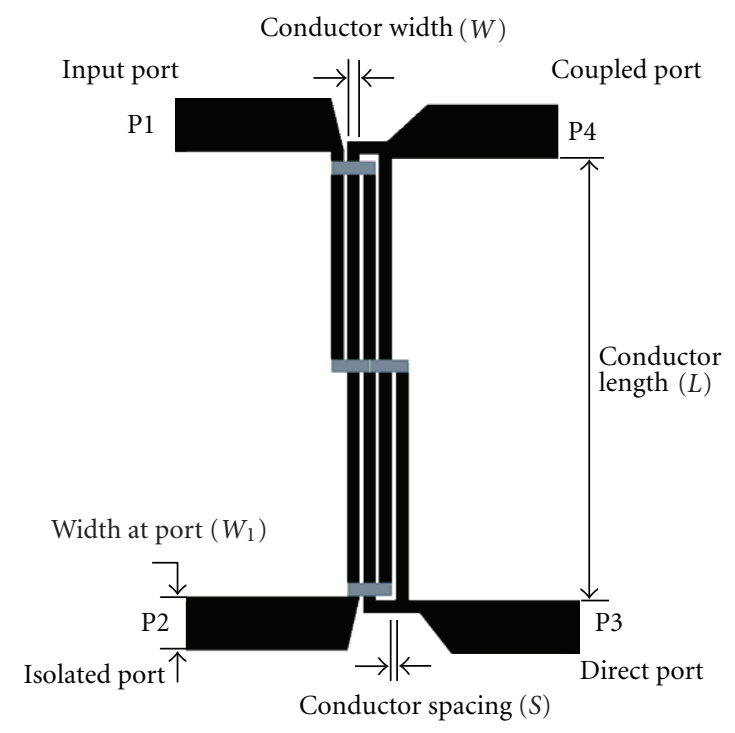

FIGURE 2: Layout of proposed Lange coupler using ADS.

via very short wires, between alternate lines of the coupler. The bond wires should be as close as possible to a short circuit to minimize the lumped inductance. Therefore, in designing this coupler, emphasis was made to minimize the effect of bonding-wire inductance and to maintain electrical symmetry [11]. In this section, the designed $-3 \mathrm{~dB}$ microstrip Lange coupler structure is composed of four interdigitated fingers. In the coupler design, the Duroid substrate of RT/Duroid 6006 with $\varepsilon_{r}=6.15$ and thickness of $1.27 \mathrm{~mm}$ is used.

Using the ADS-Momentum EM simulator [12], the evenand odd-mode impedances were calculated and then the effective dielectric constant for Lange couplers structure was determinate. The lines dimensions are calculated by using the LineCalc software of Agilent, Cal, USA. As a result, the line width $(W)$ of $350 \mu \mathrm{m}$, the conductor spacing $(S=$ $96 \mu \mathrm{m})$, and the width of $50 \Omega$ transmission line $\left(W_{1}=\right.$ $1.85 \mathrm{~mm}$ ) are obtained. The physical length of the Lange coupler is approximately equal to one quarter wavelength at the operating center frequency on the host substrate ( $L=15.11 \mathrm{~mm}$ ). The coupling between the coupler ports is controlled by the interfinger distance. The effective dielectric 


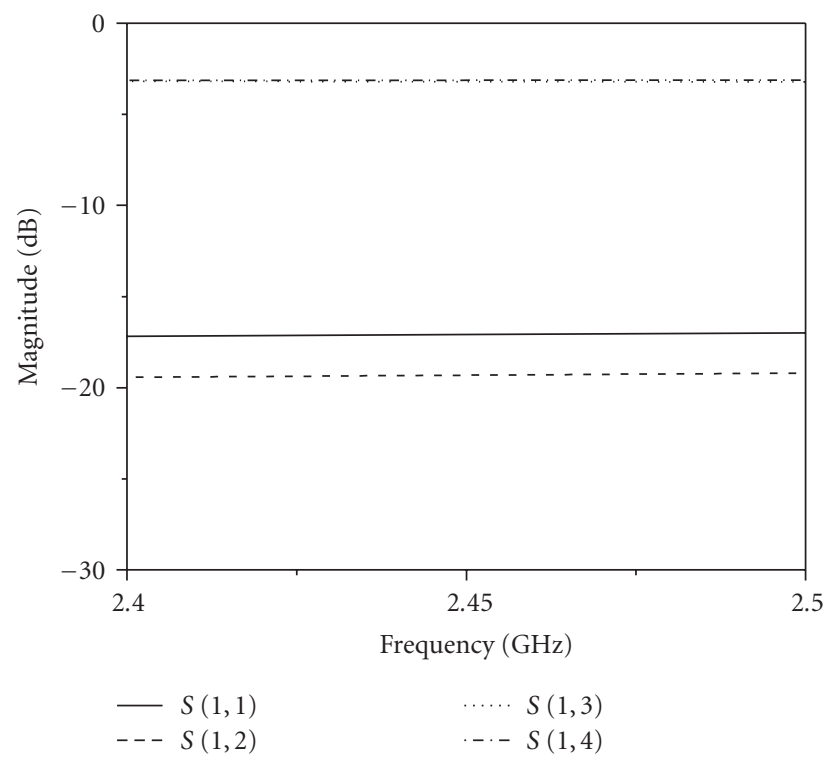

(a)

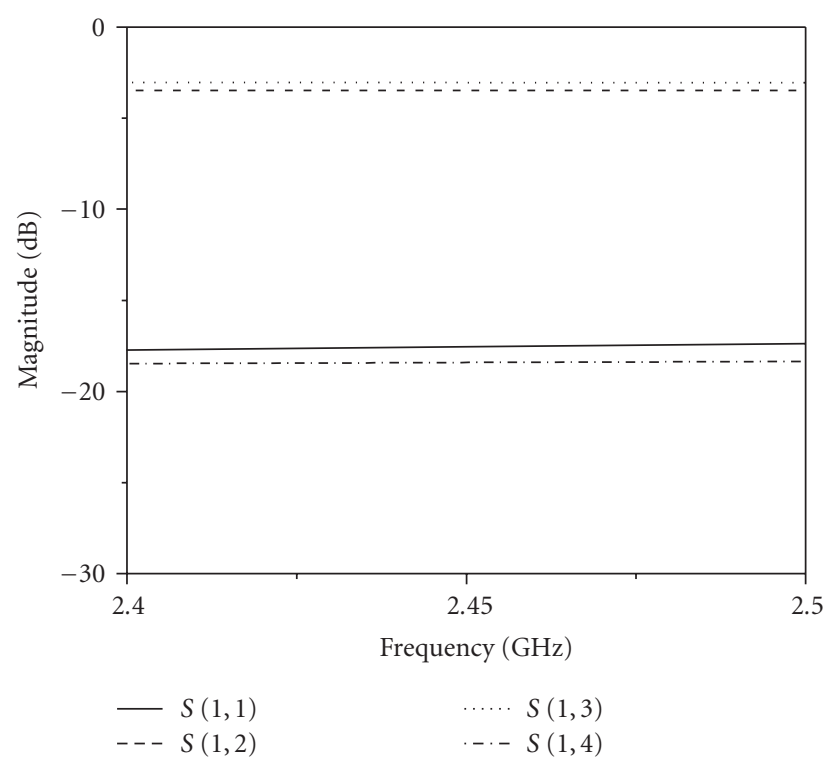

(b)

FIGURE 3: Simulated scattering parameters of a $3 \mathrm{~dB}$ Lange coupler, (a) with ADS and (b) with IE3D.

constant is computed from the length $(L)$ of the coupler used in the simulation.

The initial dimensions of the coupler were computed by using both the even- and the odd-mode analyses and LineCalc software. The optimum Lange coupler parameters are obtained by using Momentum and IE3D software. Simulation results of the return loss and insertion loss are shown in Figure 3.

The average value of the coupling for the direct port and the coupled port is $3.12 \mathrm{~dB}$, the return loss and isolation is better than $-16 \mathrm{~dB}$ and $-19 \mathrm{~dB}$. It can be seen that a $0.5 \mathrm{~dB}$

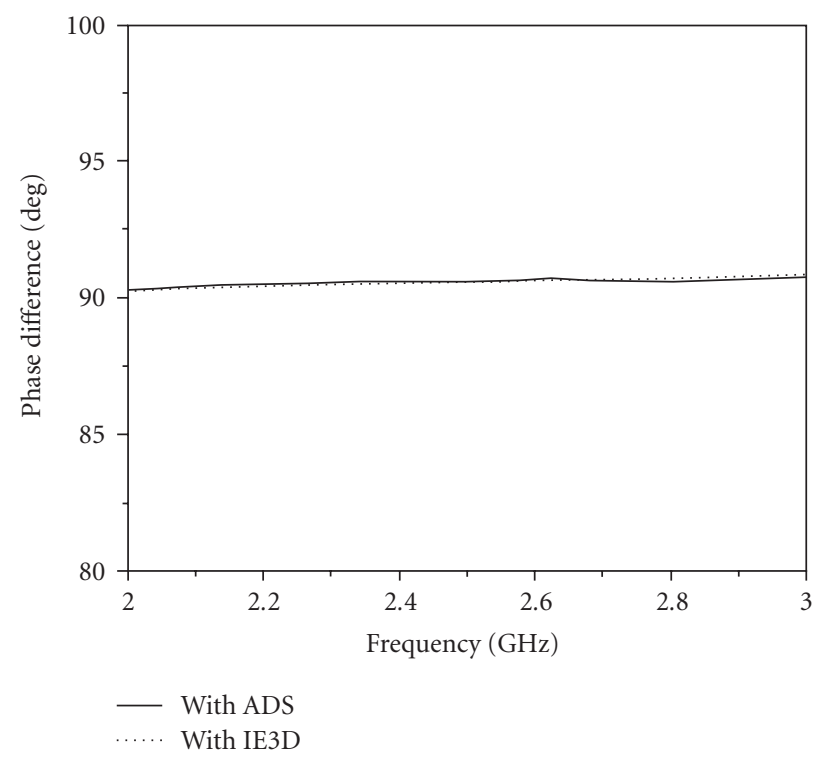

FIGURE 4: Simulation results of Lange coupler phase difference.

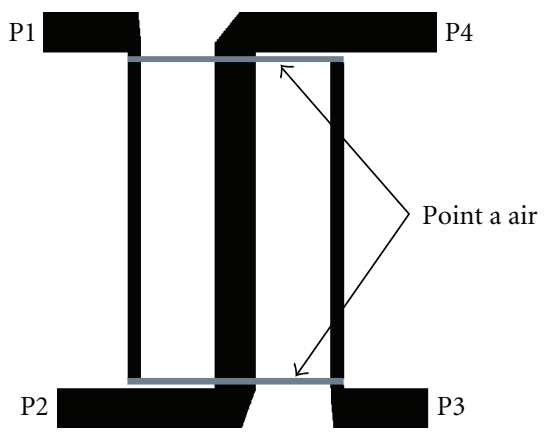

FIGURE 5: Layout of proposed Lange coupler crossover using ADS.

of amplitude imbalanced is achieved. The authors think that this value is due to the accuracy of the software.

The phase difference between the direct and coupled ports is approximatively $90^{\circ}$ across the operating band, which supports the proposed approach. Data comparisons of the simulated results show a good agreement. It can be concluded that the Lange is suitable for building Butler matrix circuits.

\subsection{Lange Coupler Crossover}

In the uniplanar implementation of Butler matrix, crossovers are one of the main drawbacks. They may add undesired effects, such as increased insertion loss, mismatched junctions, additional line cross-couplings, and poor power handling [12]. They could cause difficulty in manufacturing using conventional photolithography.

To overcome this problem, different characteristic techniques are available for the crossover design, such as in CPW designs [13], an expensive laminate is usually needed, and there is also an overhead in the fabrication and measurement processes [14]. The planar implementation is made here as 


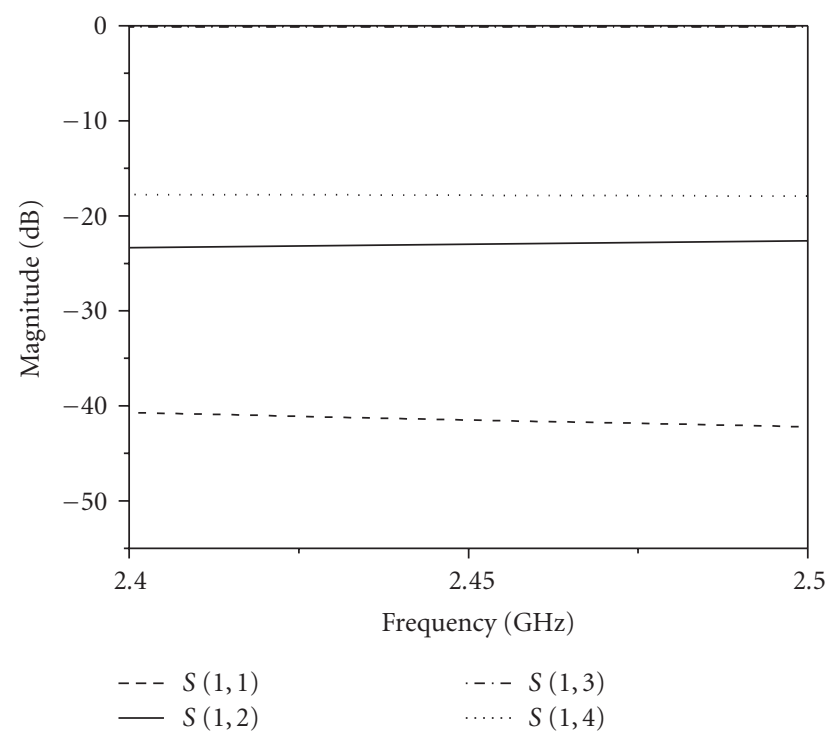

(a)

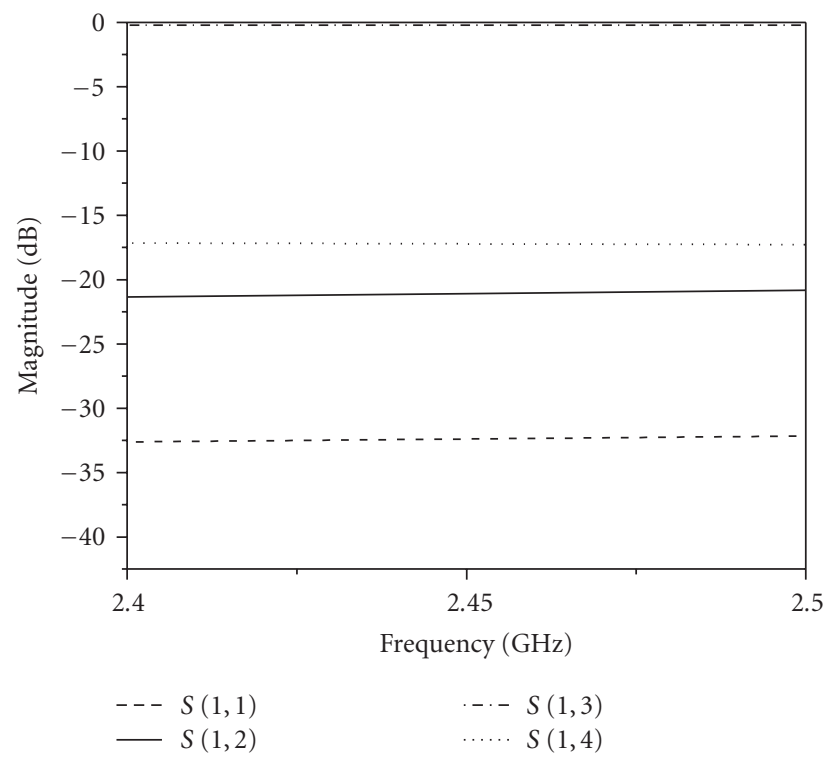

(b)

FIGURE 6: Scattering parameters of Lange coupler crossover, (a) simulation with ADS and (b) with IE3D.

a cascade of two hybrid couplers to work as a crossover. However, this structure takes more space. In our study, we use the Lange coupler reported in [15] to reduce the occupied space compared to the conventional crossovers. The Lange crossover is designed abandoned the classical form of a fouror six-finger Lange coupler. The layout of Lange crossover is shown in Figure 5.

In the design of the Lange coupler crossover, the number of fingers was reduced to three, and the number of bond wires to two [15]. The two outer fingers had a width equal to $w=0.617 \mathrm{~mm}$, while the width of the center finger was $w=1.85 \mathrm{~mm}$. It can be noted that the microstrip line has the same width of Lange coupler design. The interfinger distance

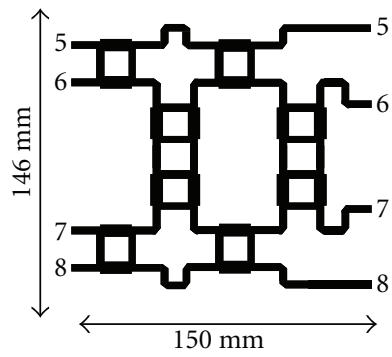

(a)

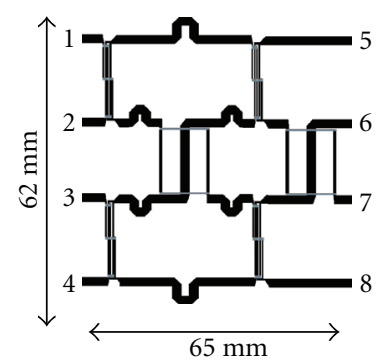

(b)
Figure 7: (a) Layout of conventional $4 \times 4$ Butler matrices. (b) Layout of the proposed $4 \times 4$ Butler matrix.

of the coupler is equal to $3.341 \mathrm{~mm}$. The bond wires are made of copper, having a width $w=0.308 \mathrm{~mm}$. In this case, two wires are used instead of one in order to make the two paths more symmetrical [16].

The broadband Lange coupler crossover was designed and optimized to have good isolation and to keep the return loss at an acceptable level. From the simulation results, the coupling is almost constant over the band and close to $-0.08 \mathrm{~dB}$, while the cross-coupling between isolated ports is less than $-19 \mathrm{~dB}$. Moreover, the return loss is less than $-36 \mathrm{~dB}$ in the band of interest, as illustrated in Figure 6.

\section{The Proposed $4 \times 4$ Butler Matrix}

The block diagram of the proposed $4 \times 4$ Butler matrix is presented in Figure 1 and its layout is shown in Figure 7. Combining the components presented in Sections 2.1 and 2.2, the proposed Butler matrix was designed using only Lange coupler device. From the dimensions of both matrices shown in Figure 7, it can be seen that the proposed structure is more compact compared to the conventional one with $80 \%$ of compactness. To demonstrate our approach, the proposed Butler matrix was designed at a frequency range of $2.45 \mathrm{GHz}$ using Rogers substrates RT/Duroid $6006\left(\varepsilon_{r}=6.15\right.$, and $h=1.27 \mathrm{~mm}$ ) as shown in Figure 7. Copper metallization for the conductive layers is $17.5 \mu \mathrm{m}$ thick. In this configuration, signals incident at input ports (no. 1, no. 2, no. 3, or no. 4) are divided into four output ports (no. 5 , no. 6 , no. 7 , and no. 8 ) with equal amplitude and specified relative phase differences.

Figure 8 show simulation results of the insertion and return loss for port 1 with two softwares (ADS and IE3D) when the other ports are matched.

These results illustrate that the return loss is better than $15 \mathrm{~dB}$ and the coupling to the output ports is well equalized (around $6.5 \mathrm{~dB}$ ). It can be concluded that the obtained results are very promising.

Figure 9 illustrates a good agreement between the simulated results of the phase shift of adjacent output ports, where

$$
\begin{aligned}
& \text { Phase difference } 1=\text { Phase }(S(5,1)-\text { Phase }(S 6,1)), \\
& \text { Phase difference } 2=\text { Phase }(S(6,1)-\text { Phase }(S 7,1)), \\
& \text { Phase difference } 3=\text { Phase }(S(7,1)-\text { Phase }(S 8,1)) .
\end{aligned}
$$




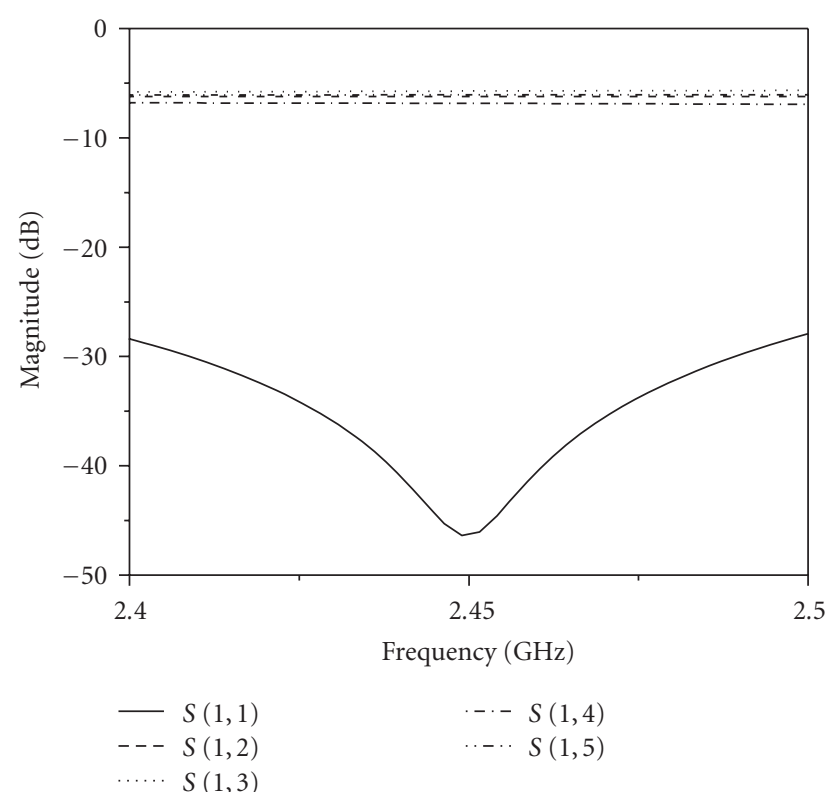

(a)

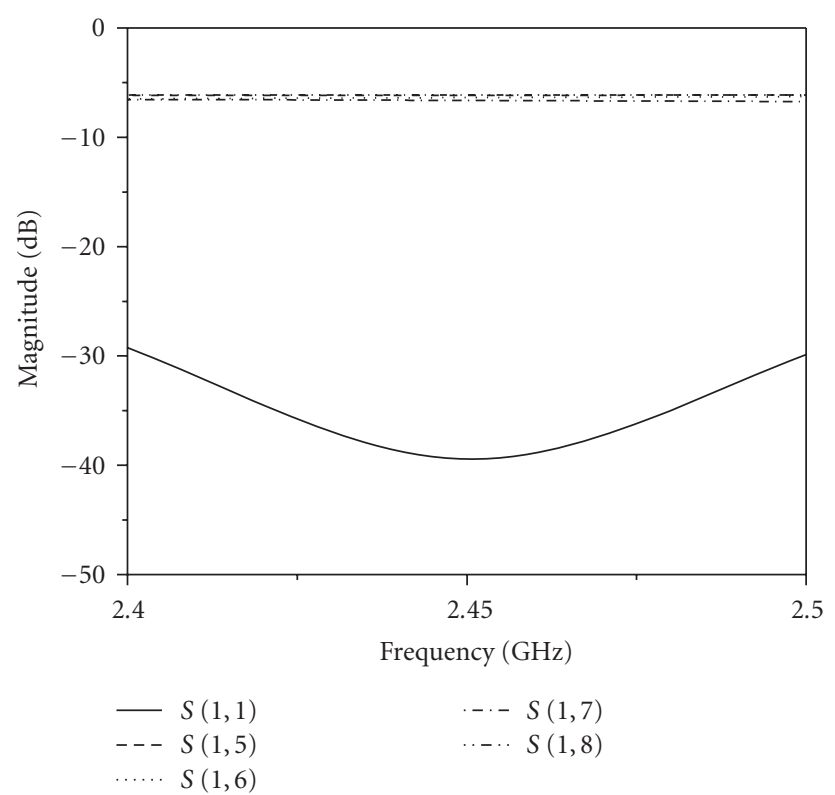

(b)

FIGURE 8: Simulated results of magnitude $S$ parameters of the $4 \times 4$ Butler matrix, (a) simulation with ADS and (b) with IE3D.

It can be seen that the phase differences are not perfectly flat in the entire bandwidth which the theoretical values are in $45^{\circ}$. The phase errors are going from $4^{\circ}(2.4 \mathrm{GHz})$ to $5^{\circ}(2.5 \mathrm{GHz})$ in all the bandwidths compared to desired value of $45^{\circ}$. These errors are due to the use of the narrowband transmission line phase shifters and crossover. To demonstrate the performance of the $4 \times 4$ Butler matrix using Lange coupler in terms of beamforming, the proposed Butler matrix is connected to antenna array [17]. This array structure has four elements spaced by $0.5 \lambda_{0}$ at $2.45 \mathrm{GHz}$ in

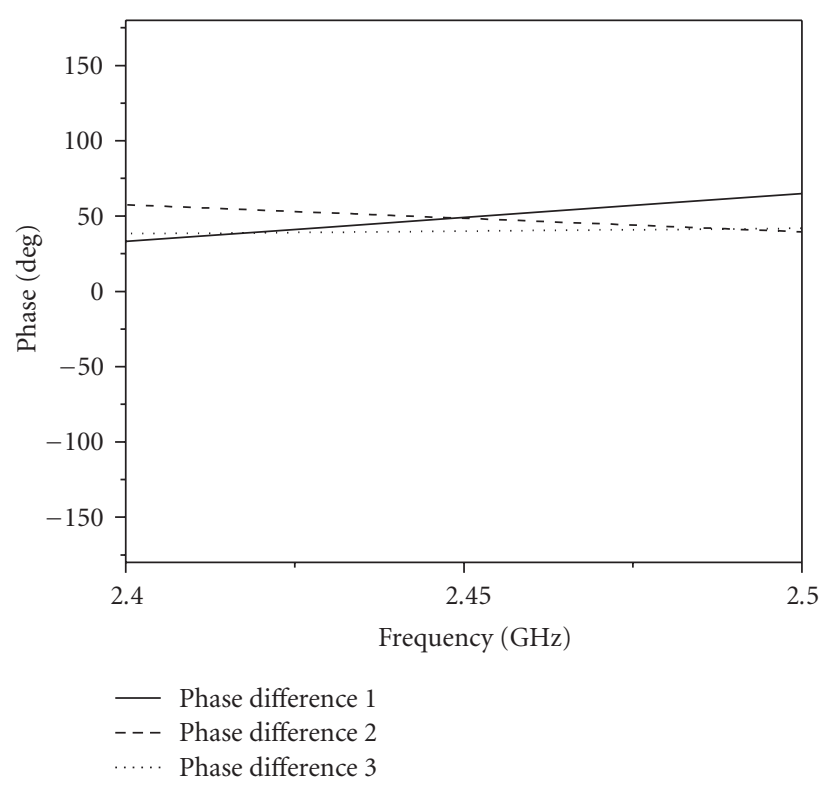

(a)

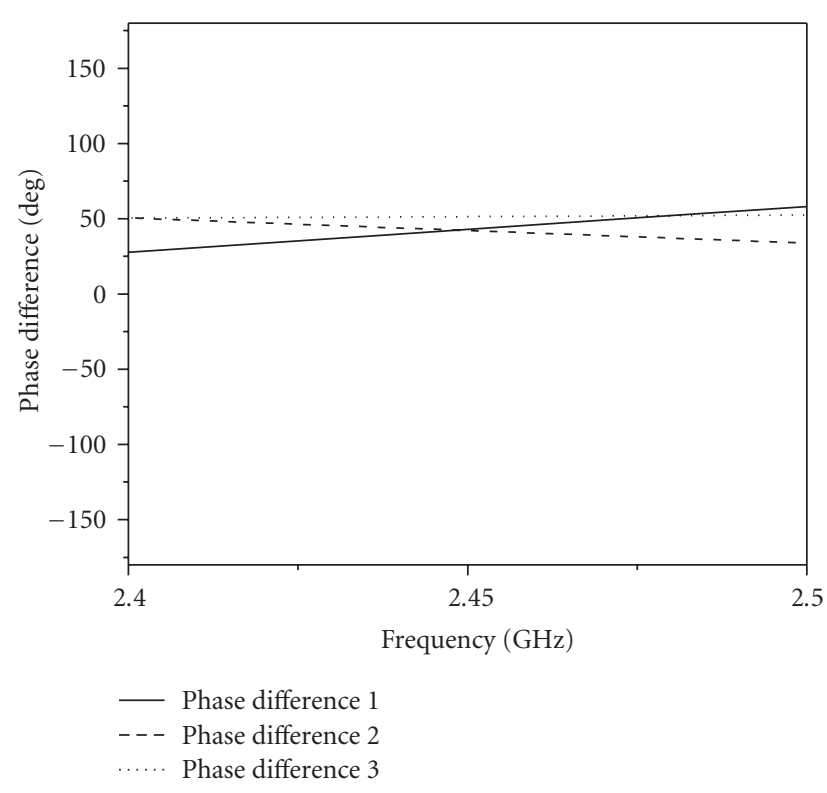

(b)

FIGURE 9: Simulated results of Butler matrix phase signal at port 1, (a) simulation with ADS and (b) with IE3D.

order to minimize the mutual coupling between elements and to obtain the minimum level side lobes. As a result, the array has uniform amplitude distribution and constant phase shift between adjacent elements to generate orthogonal beams.

Figure 10 shows the simulated results of radiation patterns in the $\mathrm{H}$-plane of the beamforming antenna array system at $2.45 \mathrm{GHz}$, these numerical results take into account the mutual coupling between element arrays. With this matrix, four beams are produced at $-45^{\circ},-15^{\circ}, 15^{\circ}$, and 


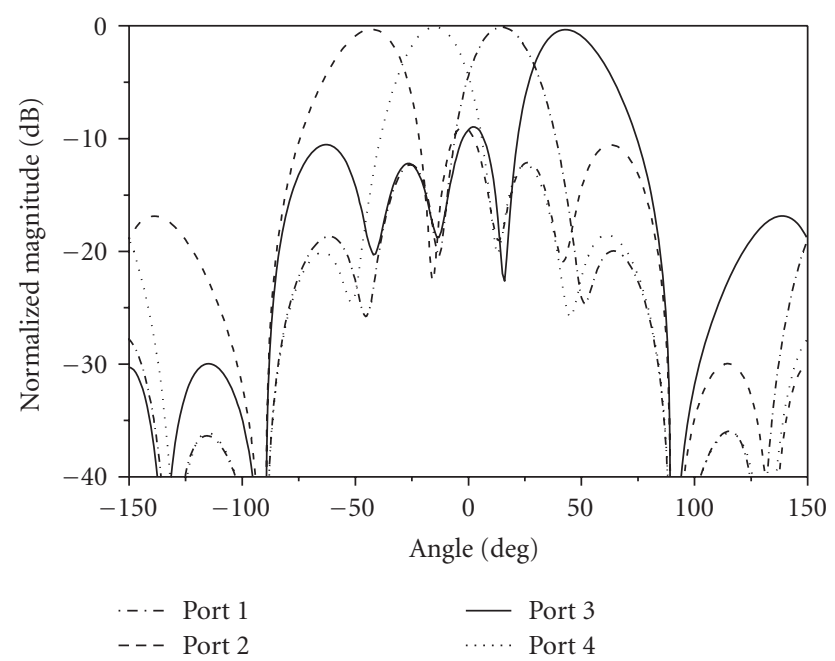

(a)

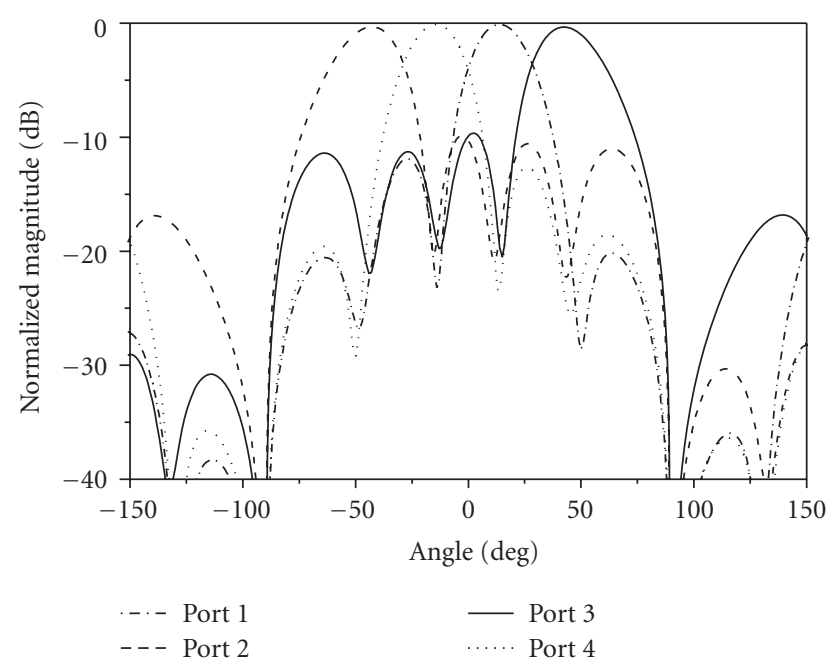

(b)

FIGURE 10: Simulated H-plane radiation pattern with (a) ADS and (b) IE3D.

$45^{\circ}$. Simulation results indicate a good agreement with the theoretical prediction. These features make the proposed matrix suitable for beamforming applications.

\section{Conclusion}

A compact $4 \times 4$ Butler matrix on a single-layer with relatively negligible cost has been designed. The circuit is compact with $80 \%$ of size reduction compared with conventional structure. In the proposed design, Lange coupler and Lange crossover have been used as a key component of new topology, which leads to significant size reduction and loss minimization. Simulated results are validated by using the software tools IE3D and Momentum. Furthermore, a four-antenna array has also been designed and connected to the proposed Butler matrix to form a beamforming system resulting in fourorthogonal beams $-45^{\circ},-15^{\circ}, 15^{\circ}$, and $45^{\circ}$ at $2.45 \mathrm{GHz}$.
The proposed system has the advantages of low cost, small volume, and light weight. These features make the proposed Butler matrix suitable for ISM applications at $2.45 \mathrm{GHz}$.

\section{References}

[1] W. C. Liu, "Optimal design of dualband CPW-FED Gshaped monopole antenna for WLAN application," Progress in Electromagnetics Research, vol. 74, pp. 21-38, 2007.

[2] T. A. Denidni and T. E. Libar, "Wide band four-port Butler matrix for switched multibeam antenna arrays," in Proceedings of the 14th IEEE International Symposium on Personal, Indoor and Mobile Radio Communications (PIMRC '03), vol. 3, pp. 2461-2464, Beijing, China, September 2003.

[3] T. Hirota, A. Minakawa, and M. Muraguchi, "Reduced-size branch-line and rat-race hybrids for uniplanar MMIC's," IEEE Transactions on Microwave Theory and Techniques, vol. 38, no. 3, pp. 270-275, 1990.

[4] T. K. G. Kwang and P. Gardner, " $4 \times 4$ Butler matrix beam forming network using novel reduced size branchline coupler," in Proceedings of the 31st European Microwave Conference (EuMC '01), pp. 1-4, London, UK, September 2001.

[5] M. Bona, L. Manholm, J. P. Starski, and B. Svensson, "Lowloss compact Butler matrix for a microstrip antenna," IEEE Transactions on Microwave Theory and Techniques, vol. 50, no. 9, pp. 2069-2075, 2002.

[6] K. Wincza and S. Gruszczynski, "A broadband $4 \times 4$ Butler matrix for modern-day antennas," in Proceedings of the 35th European Microwave Conference, vol. 2, pp. 1331-1334, Paris, France, October 2005.

[7] T. N. Kaifas and J. N. Sahalos, "On the design of a single-layer wideband Butler matrix for switched-beam UMTS system applications," IEEE Antennas and Propagation Magazine, vol. 48, no. 6, pp. 193-204, 2006.

[8] M. Ueno, "A systematic design formulation for Butler matrix applied FFT algorithm," IEEE Transactions on Antennas and Propagation, vol. 29, no. 3, pp. 496-501, 1981.

[9] G. F. Khodae, J. Nourinia, and C. Ghobadi, "A practical miniaturized U-slot patch antenna with enhanced bandwidth," Progress in Electromagnetics Research B, vol. 3, pp. 47-62, 2008.

[10] J.-J. Wu, "A multimode interference coupler with exponentially tapered waveguide," Progress in Electromagnetics Research C, vol. 1, pp. 113-122, 2008.

[11] HP-ADS, Momentum Users Manuel, Palo Alto, Calif, USA, Agilent Technologies, 2005.

[12] M. Nedil, T. A. Denidni, and L. Talbi, "Novel Butler matrix using CPW multilayer technology," IEEE Transactions on Microwave Theory and Techniques, vol. 54, no. 1, pp. 499-507, 2006.

[13] T. Mbarek, N. Fadlallah, and G. Ali, "Performance comparison of $3 \times 4$ Butler matrices designed with $0 \mathrm{~dB}$ couplers and bi-layer microstrip technology," The Mediterranean Journal of Electronics and Communications, vol. 3, no. 4, pp. 152-158, 2007.

[14] A. R. Mallahzadeh, A. A. Dastranj, and H. R. Hassani, "A novel dual-polarized double-ridged horn antenna for wideband applications," Progress in Electromagnetics Research B, vol. 1, pp. 67-80, 2008.

[15] T. N. Kaifas and J. N. Sahalos, "A $4 \times 4$ Butler matrix optimized for umts applications," Microwave and Optical Technology Letters, vol. 49, no. 3, pp. 585-588, 2007. 
[16] M. Nedil, T. A. Denidni, and L. Talbi, "Design of a broadband slot antenna fed by CPW for wireless application at $5.8 \mathrm{GHz}$," in Proceedings of the IEEE Vehicular Technology Conference (VTC '04), vol. 1, pp. 18-21, Milano, Italy, May 2004.

[17] J. He, B.-Z. Wang, Q.-Q. He, Y.-X. Xing, and Z.-L. Yin, "Wideband X-band microstrip Butler matrix," Progress in Electromagnetics Research, vol. 74, pp. 131-140, 2007. 

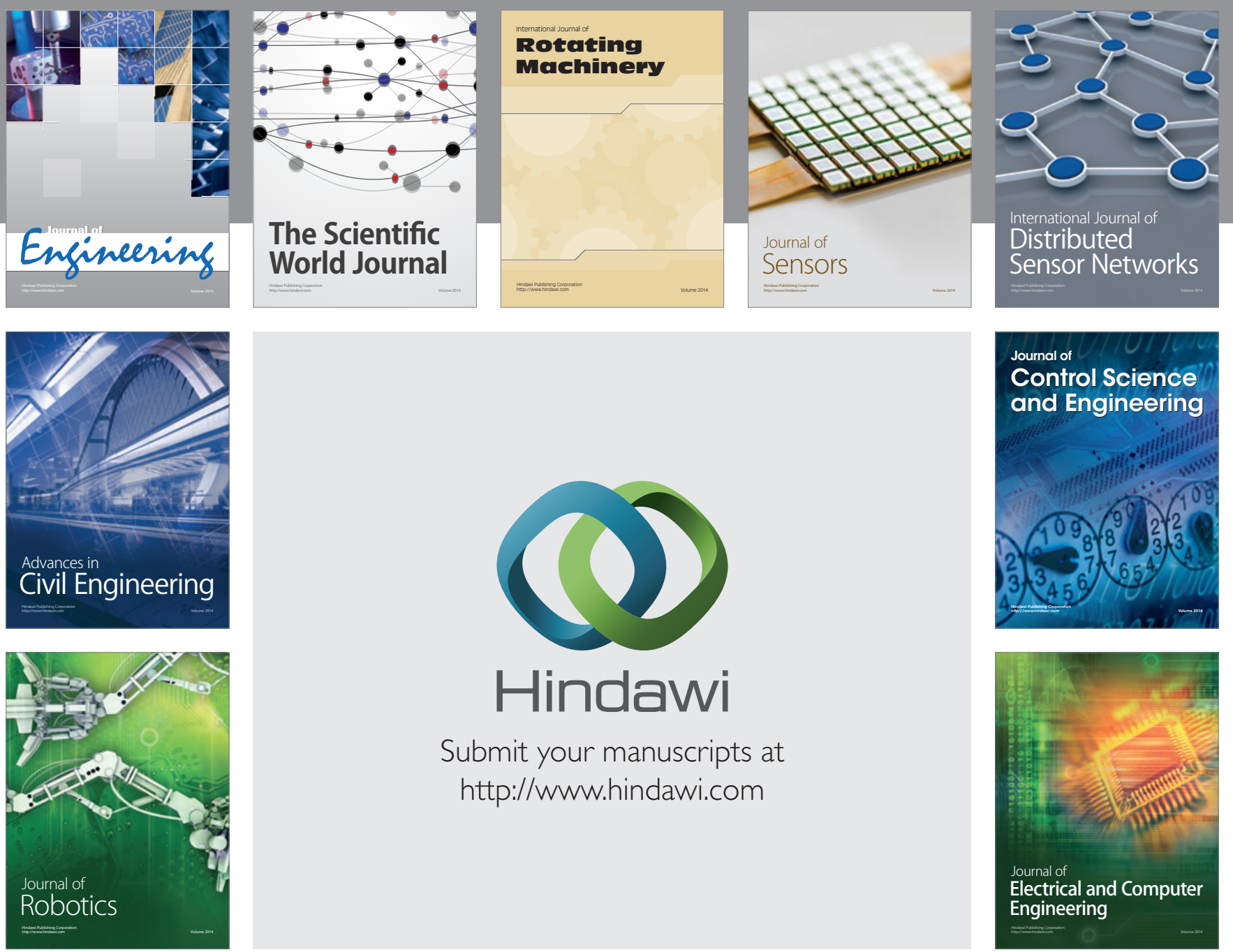

Submit your manuscripts at

http://www.hindawi.com
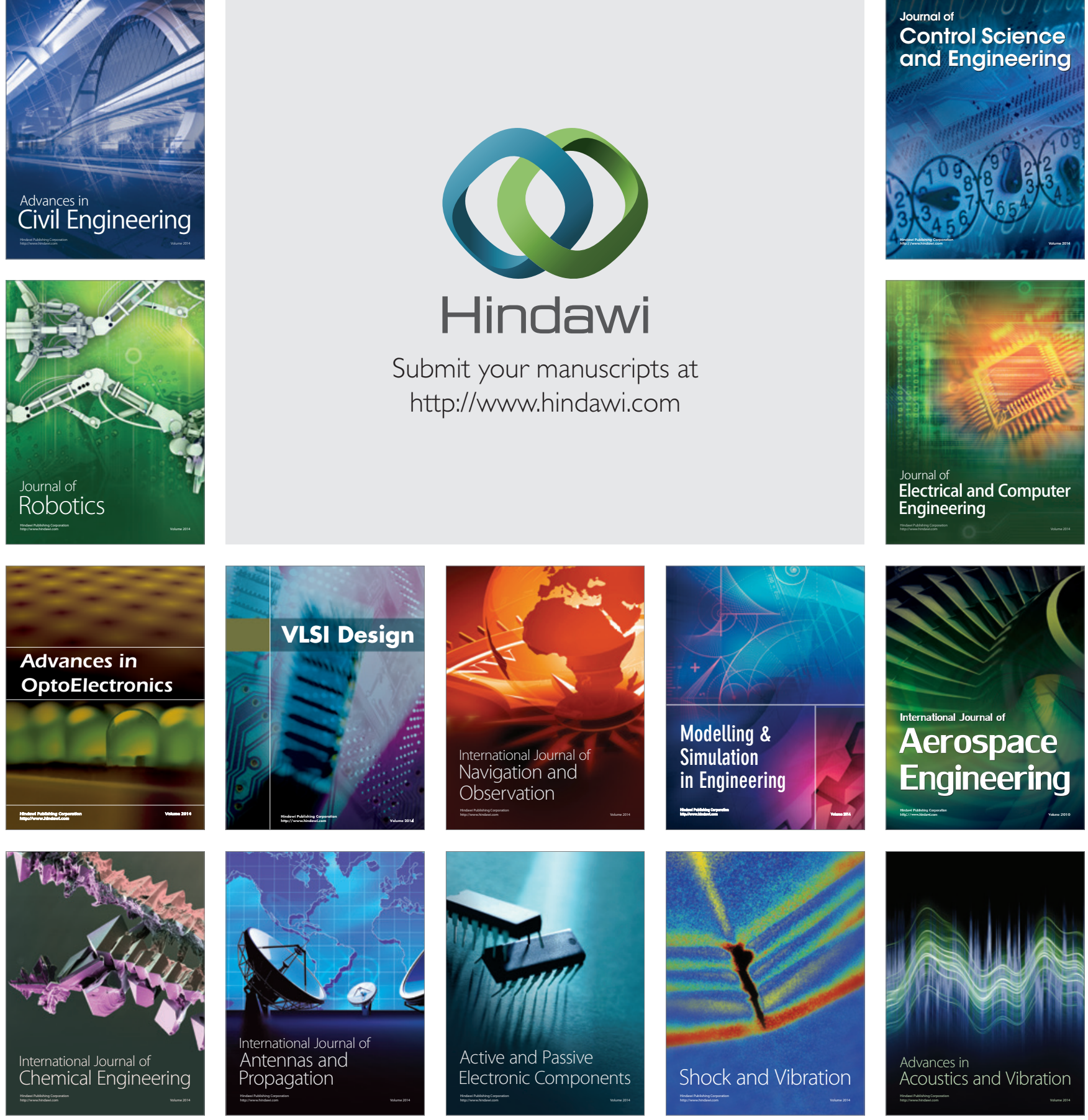